\title{
An Analysis of Non-English Major Freshmen's Language Fossilization Jiaoyan Yang ${ }^{1, a}$ and Xue Peng ${ }^{1, b}$ \\ ${ }^{1}$ School of Humanities, Sichuan Agricultural University, Chengdu, Sichuan Province, China a937653817@qq.com, b17008182@qq.com
}

Keywords: Interlangue, Fossilization, Non-English Major Freshman, Imput

\begin{abstract}
The paper aims to probe into the causes of language fossilization based on classroom observation, interviews of non-English major freshmen and analysis of their errors made in their composition. In addition, the paper also attempts to present some effective counter-measures to help non-English major freshmen overcome language fossilization.
\end{abstract}

\section{Introduction}

It is Selinker(1972), an American linguist, who has first proposed the jargon of "fossilization", which refers to a kind of language phenomenon that numerous fixed language errors are repeated so many times so that language learners experienced a "plateau" period in which language learners acquire the language slowly, and what is worse, their language development ceases before they survive the period and their learning curve rises once again. Selinker also declares that as many as 95 percent of second language learners will encounter the fossilization during their language learning process. On the grounds of it, language learners find it hard for them to make progress in their language acquisition despite their strong motivation and hard work, which is frustrating to both the language learners and instructors. As a result, non-English major freshmen and college English learners are no exception and they are definitely plagued by the phenomenon. Consequently, it is significant theoretically and practically to research language fossilization for it cannot only deepen people's understanding of the phenomenon, but also help language learners and instructors overcome it and achieve language proficiency. As a matter of fact, fossilization, as one phenomenon in the acquisition of language, has already aroused many researchers' attention. To illustrate, many researchers have attempted to define and illustrate language fossilization. The paper aims to probe into the causes of language fossilization based on classroom observation, interviews of non-English major freshmen and analysis of their errors made in their composition. In addition, the paper also attempts to present some effective counter-measures to help non-English major freshmen overcome language fossilization.

\section{Introduction to Interlanguage}

When it comes to the study of language fossilization, it is inevitable to begin with interlanguage for language fossilization is one of the major issues in the system of interlanguage. Literally, it is easy to conclude that interlanguage is a special type of language which is constructed based on the two language system for "inter" means middle or in-between in English. From its literal meaning, it can be seen that interlanguage differs from the two languages although it is based on them. In other words, there are some similarities and dissimilarities between interlanguage and the two languages owing to the language learners' motivation, environment, learning competence, perseverance, etc. Precisely, Selinker supposes that "An interlanguage may be linguistically described using as data: the observable output resulting from a speaker's attempt to produce a foreign norm, i.e. both his errors and non-errors. It is assumed such behavior is highly structured" [1]. And he maintains that interlanguage is a language system which is different from both the learner's native language and the target language.[2] Namely, he regards it as a distinctive language system which is created by the language learners' incomplete production of the second language norms. The proposal of interlanguage is epoch-making for it is the first time that language researchers have attempted to 
explore and explain the mental process that the learners acquire the second language.

Based on Selinker's research, many relevant researches have been conducted. MacLaugh points out " Interlanguage has come to characterize a major approach to second language research and theory".[3] Furthermore, Ellis (1994)summarizes the three distinctive characteristics of the interlanguge system: permeable, dynamic and systematic.[4] Specifically, the interlanguge is permeable in that it is fixed and prone to be amended; it is dynamic in that the interlanguage is in the constant process of revision for the language learners adjust its structure to their newly-formed hypothesis of the second language; it is systematic for the second language usage is still rule-based although the interlanguage constantly changes..

\section{Introduction to Fossilization}

"Fossilization”, initially a geographical term indicating the forming process of organism fossils, is first proposed and adopted by Selinker in 1972 to describe repeatedly occurring language phenomena in the process of language acquisition, especially the second language acquisition. Based on his researches, Selinker maintains that the majority of second language learners cannot have the same acquisition of the language as the native speakers. He defines fossilization as "linguistic phenomena are linguistic items, rules and subsystems which speakers of a particular native language will tend to keep in their interlanguage relative to a particular target language, no matter what the age of the learner or amount of explanation and instruction he receives in the target language [2], which is still universally accepted in the second language acquisition. From the cognitive perspective, Selinker views fossilization as one of the hidden psychological structures' constituents, which demonstrates the language learners competence of a language, especially a second language. Form the other perspective, he considers fossilization as a structural notion relating performance, representing "the regular reappearance in second language performance of linguistic phenomena which were thought to be eradicated in the performance of the learner"[3]. The two aspects of fossilization are thought to be interrelated. After proposing the concept of "interlanguage", Selinker further defines fossilization as "a permanent cessation of interlanguage learning before the learner has attained target language norms at all levels of linguistic structure and in all discourse domains in spite of the learner's positive ability, opportunity, and motivation to learn and acculturate into target society"[5].

From the perspective of the second language acquisition, fossilization can be divided into individual fossilization and group fossilization on the basis of its form. Individual fossilization refers to the various fossilized language expressions adopted by individual language learners or the various extent of fossilized competence of the target language demonstrated by individual language learners. Moreover, individual fossilization can be further classified as error fossilization, which means the recurring improper interlanguage of the language beginners or language learners of poor proficiency despite the numerous corrective feedbacks, and language competence fossilization, which refers to the fossilization of the interlanguage's pronunciation, vocabulary, syntax and pragmatics, etc. occurring to the second-language learners with high proficiency or the learners who have learned the target language for many years. When a second language learner cannot notice and correct the improper usage in the interlanguage, he or she makes the mistake of language competence fossilization. In effect, there is no clear boundary between error fossilization and language competence one for language competence fossilization is reflected by error fossilization. That is why the research of language competence fossilization is conducted by accumulating and analyzing the repeatedly occurring errors in the interlanguage. Group fossilization, as the name suggests, refers to the fossilized language expressions employed in a whole society or community, thus formulating a different dialect from other communities, such as Indian English, Singapore English. The research of group fossilization can offer some inspirations to the one of individual fossilization. Given its duration, the fossilization can be divided into the temporary one and the permanent one, which are clear enough to show their meanings respectively. According to Dai Weidong and Niu Qiang (1999), the fossilization made by the majority of China's 
English learners falls into the temporary one [6], which is the subject of the research.

\section{Non-English Major Freshmen's Language Fossilization}

Classroom is the most common and place where non-English major freshmen learn English, thus an effective and sufficient classroom observation can supply the authentic first-hand data for the research of non-English major freshmen's Language Fossilization. Classroom observation conducted in this study is confined to the course of English only with 60 subjects. Other data collected from the interview and from the composition of the 60 subjects are to be analyzed in order to compensate for the explanations of errors made by non-English major freshmen in the classroom.

Through classroom observation, it has been found that the participation of non-English major freshmen in the language instruction varies with the design of the teaching. The participation of the freshman is rather low when the English instructions are conducted in a traditional way with stable given stages: words and phrases, texts, difficult points, and oral or written practice, which are conducted with blackboard writing, the involvement of PPT and the oral instruction of the teacher. On the other hand, the freshmen participate more when the English teacher adopts the audio and video materials, especially the video materials, and requires them to imitate some of the video clips, or to discuss what they have seen on the video. In other words, in the teacher-centered class, non-English major freshmen are passive language learners with the teacher as the only source of language input; in the student-centered class, they are active learners with their individual ideas expressed and others' views considered, who can better understand the teacher with the information from the audio and video materials. Meanwhile, in the teacher-centered class, the mood of the non-English major freshmen dose not fluctuate during the entire process of learning, which leads to a serious class atmosphere in which students feel very tense, and in the student-centered class, the freshmen are enthusiastic and initiative, appearing to be confident, relaxed during the learning process and to be interested in the subsequent learning.

Compositions written in class by 60 subjects are collected to find the language fossilization of the non-English major freshmen. During the whole course of writing, no discussion is conducted among the students or between the teacher and the students. The compositions should involve the common college life or hot social issues, such as "How to build a green campus?", "The Impact of the Cell-phone on Interpersonal Communication". All the compositions that the freshmen are required to write are argumentative writings. The error fossilization in the compositions is demonstrated in the following aspects: punctuation, lexicon, morphology and syntactic. When it comes to punctuation, the unique punctuation marks such as“、”, “。”, ““《》” "are widely used in the compositions. Furthermore, the comma is mistakenly used to connect two sentences in the compositions under the negative influence of Chinese, for in Chinese it is the most frequently used punctuation mark to separate sense groups, even sentences. When it comes to lexicon, misspelling is common, such as misspelling of one or two letters in the word, the coined new words which are inconsistent with the writing standard of the English language. When it comes to morphology, inappropriate use of some morphemes can lead to ambiguous or awkward expressions. For example, "unnecessary wastes should be avoided" is clumsy for no wastes are necessary. Improper collocations are also common, for example, the freshmen use "learn knowledge" instead of "acquire knowledge", and "cheap price products" rather than "products of low price". When it comes to syntactic, some typical Chinese sentence patterns are adopted in the composition. In the first place, the sentence patterns with passive meanings and active forms, which are typical in Chinese, are employed in the composition. For example, "the precious resources will soon use up if we don't take some measures to protect". In the sentence, the object behind the transitive verb "protect" is not written out for it can be omitted in Chinese as long as it is implied between the lines. But in English the usage of "protect" without the object after it is considered grammatically wrong. Besides, more coordinated sentence structures that are characterized in Chinese are used in the freshmen's composition instead of the subordinated ones that are characteristic in English. For 
example, " His family is poor and lacks food and clothes, he dropped out of school, he found a work and he supported his family." is used instead of "He dropped out of school to find a work supporting his family for his family is so poor that they lack food and clothes."

By interviewing the 60 students, it can be founded that the non-English major freshman lack the motivation to study English for they think it is meaningless to learn it or they study it just in order to pass the exam. As a result, they are passive in their language learning.

Based on data collected, it can be concluded that some internal elements, such as the participation and the motivation of the subjects, and some external elements, such as negative transfer of mother tongue, lack of authentic language input, improper input mode and imbalanced input content, contributes to the English fossilization of the non-English major freshmen. As far as participation is concerned, the non-English major freshmen's participation in the English class is insufficient for they are accustomed to passive learning and are not exposed to innovative inspiring teaching methods. As a result, they just mechanically imitate the language patterns without their personal active participation in the classroom instruction, thus not grasping the essence of the language learning. The motivation of the majority of non-English major freshmen is to pass CET 4. Through the interviews, some factors that impact the learning motivation are the freshmen's lack of learning methods, self-discipline and persistence, the boring teaching materials and the inappropriate learning atmosphere. The subjects interviewed declare that these factors have a negative effect on their motivation to acquire English, which gives rise to the stagnation of their English acquisition. Negative transfer of mother tongue refers to the improper application of pronunciation, vocabulary and syntax of mother language when the learners' language competence is insufficient to express themselves in the target language. There are between the Chinese language and the English language great differences, which makes it tough to acquire the second language. Based on the classroom observation, there is lack of authentic language input for the non-English major freshmen still focus on the command of vocabulary and grammar and the teaching methods are obsolete. The mode of the language input is inappropriate and its content is imbalanced. The language input is mainly by the mode of reading instead of listening, which hinders the language learners' communication with others for they cannot understand others. And the content of input is chiefly written English instead of everyday English so they cannot come up with the proper expressions to express themselves.

There are some suggestions intending to relieve the language fossilization of the Non-English major freshmen. In the first place, the freshmen should learn more about the differences of the English language and the Chinese Language so as to overcome the negative transfer of their mother tongue. Teachers can give lectures on the discrepancies of the semantic system, thinking ways, values and other aspects between Chinese and English and organize students to discuss these issues to promote the students' participation. Secondly, with the aid of multi-media, teachers present more authentic language input to the students, so that their interests in the English learning can be boosted and the learning materials can be easily internalized in the form of video. Thirdly, the English language input structure should be balanced. Rost maintains that the auditory input can not only inspire the brain, but also take charge of balance and timing[7]. Consequently, auditory input should be increased to enable the language learners to make the most of biological elements to improve their proficiency of English efficiently for it can activate numerous parts of the brain and reinforce its vitality. In addition, diversified language input should be conducted for it can stimulate diverse corresponding parts to boost the language acquisition. Last but not least, strong and positive motivation of language learners should be cultivated on purpose. Teachers can organize some competitions to boost the instrumental motivation of the students. Or they can innovate their teaching methods and adopt various interesting language materials to arouse the students' interest in language learning, thus inspiring their integrative motivation.

\section{Conclusion}

Fossilization is a recurring language phenomenon in interlanguage, which is caused by some 
internal elements, such as the participation and the motivation of the subjects, and some external elements, such as negative transfer of mother tongue, lack of authentic language input, improper input mode and imbalanced input content. It is inevitable in the acquisition of the second language, but it can be relieved by reducing the negative transfer of the mother tongue, taking authentic language materials as language learning materials, balancing language input structures and cultivating strong and positive motivations. Fossilization is an important language phenomenon worth wide attention for the relieving of fossilization can greatly promote the mastery of the second language. More researches are necessary to deepen the understanding of fossilization and to find suitable approaches to overcome it.

\section{Acknowledgement}

I am greatly indebted to my families for their support and understanding when I am absorbed in the research. My thanks go to my colleagues as well for their useful suggestions are of great assistance to my draft of the paper.

\section{References}

[1] Selinker, L. Language Transfer [J]. In General Linguistics, Vol.9, 1969 (2):67-92.

[2] Selinker, L. and Lakshmanan. J. Language Transfer and Fossilization: The Multiple Effects Principle [A]. Language Transfer in Language Learning. Amesterdam: John Benjamins Publishing Company, 1972.

[3] McDonough, S. Psychology in Foreign Language Teaching. [M]. London: Allen and Unwin.1981.

[4] Ellis, R. The Study of Second Language Acquisition [M]. Oxford University Press. 1994.

[5] Selinker, L. \& Lamenguage J. T. "Two perspectives on fossilization in interlanguage”. In Interlanguage Studies Bullettin, 1978, 3:187.

[6] Dai Weidong \& Niu Qing. Research on Fossilization in Interlanguage and Its Inspiration to Teaching [J]. Foreign Language Research, 1999, (2)

[7] Rost, M. Teaching and Researching Listening [M]. Beijing: Foreign Language Teaching and Research Press, 2005. 